\title{
Nuclear energy in the context of climate change
}

\author{
Vasile Popa $^{1}$ iD, Octavian Cocoș ${ }^{1}$ \\ ${ }^{1}$ University of Bucharest, Faculty of Geography, 1 Nicolae Bălcescu Avenue, 010041 Bucharest, Romania; \\ e-mail: popavasile2005@yahoo.com (V.P.); octaviancocos@yahoo.com (O.C.)
}

Received: 21 September 2021; Revised: 18 October 2021; Accepted: 26 October 2021;

Published online: 3 November 2021

\begin{abstract}
Human society faces the great challenge of drastically reducing greenhouse gas emissions while providing increased amounts of energy. Although the share of renewable energy sources has increased in recent years, fossil fuels are still widely used and burning them makes large amounts of carbon dioxide enter the atmosphere. However, renewable energy sources may not be able to supply in time enough energy to replace fossil fuels. Under the circumstances, the question arises as to whether nuclear energy could play a significant role in mitigating climate change. Although there is still confidence and support for nuclear energy, it is unlikely that this energy source will make a greater contribution to combating climate change in the coming decades. This study analyzes the current state of nuclear energy, as well as the development prospects in the context of climate change and risks to the environment and human health.
\end{abstract}

Key words: fossil fuels, climate change, renewable energy, nuclear energy, nuclear reactors

Citation: Popa, V., \& Cocoș, O. (2021). Nuclear energy in the context of climate change. Central European Journal of Geography and Sustainable Development, 3(2), 17-25. https://doi.org/10.47246/CEJGSD.2021.3.2.2 